\title{
Theoretical and experimental photophysical studies of the tris(4,4,4-trifluoro-1-(1-naphthyl)-1,3-butanedionate) (2,2'-bipiridyl)-europium(III)
}

\author{
S.P. Vila Nova ${ }^{a, *}$, H.J. Batista ${ }^{a}$, S. Alves Jr. ${ }^{\text {a }, \text { C. de Mello Donegáa }}$, \\ R.L. Longo ${ }^{\mathrm{a}}$, G.F. de Sáa ${ }^{\mathrm{a}}$ L.C. Thompson ${ }^{\mathrm{b}}$ \\ ${ }^{a}$ Departamento de Química Fundamental, Universidade Federal de Pernambuco, Cidade Universitária, 50740-540 Recife, PE, Brazil \\ ${ }^{\mathrm{b}}$ Department of Chemistry, University of Minnesota, Duluth, MN, USA
}

Received 24 March 2005

Available online 10 August 2005

\begin{abstract}
The complexes tris(4,4,4-Trifluoro-1-(1-naphthyl)-1,3-butanedionate) (2,2'-bipiridyl) $\operatorname{Ln}(\mathrm{III}), \mathrm{Ln}(\tan )_{3}$ bipy, where $\mathrm{Ln}(\mathrm{III})=\mathrm{Eu}^{3+}$ and $\mathrm{Gd}^{3+}$ have been synthesized, characterized and their photophysical properties (absorption, excitation and luminescence spectra and emission quantum yield) investigated down to $4.2 \mathrm{~K}$. The $\mathrm{Eu}(\tan )_{3}$ bipy complex has its molecular structure experimentally determined using X-ray crystallography and theoretically using the SMLC/AM1 method as well as their electronic singlet and triplet states were calculated, using the INDO/S-CI method with a point charge model to represent the $\mathrm{Eu}^{3+}$ ion, where two values were adopted, $+3.0 e$ and $+3.5 e$, to investigate the imperfect shielding of the $4 \mathrm{f}$ shells. The so calculated $+3.5 e$ model electronic absorption spectrum and low lying triplet state energies agreed very well with the experimental ones. The emission quantum yield of the $\mathrm{Eu}^{3+}$ complex is quite low at room temperature, namely $7 \%$, probably due to the too low lying triplet state, $19,050 \mathrm{~cm}^{-1}$, and increases by a factor of three when the temperature is lowered to $4.2 \mathrm{~K}$. This strong thermal effect indicates the presence of a channel deactivating the main emitting state, what can be due to a LMCT state possibly lying in the same spectral region, as usually found in $\mathrm{Eu}^{3+}$ compounds.
\end{abstract}

(C) 2005 Elsevier B.V. All rights reserved.

Keywords: Lanthanide complexes; Emission quantum yield; INDO/S-CI

\footnotetext{
*Corresponding author. Tel.: + 558121268440 ; fax: +558121268442

E-mail address: spvn@globo.com (S.P. Vila Nova).
}

\section{Introduction}

In recent years there has been an increasing interest in the search for efficient light-converting devices based on rare-earth coordination compounds. Efficient light-conversion molecular devices 
(LCMDs) may find several applications such as luminescent probes in photosensitive bioinorganic compounds [1] and fluoroimmunoassays [2-3], fluorescent lighting [4], luminescent sensors for chemical species [5], electroluminescent devices, UV dosimeters [6], or antireflection coatings for solar cells [7]. In addition to the emission quantum yield of LCMD, other aspects, such as light output, solubility, volatility, photo and thermal stabilities as well as thermodynamic and kinetic stabilities, may be critical to many applications and must be controlled as well.

In order to gain insight into the factors that determine the quantum yield and other relevant properties of lanthanide complexes our group has been investigating the photophysical properties of a number of new lanthanide complexes, using an approach based upon both theoretical and experimental work [8-17]. The results have shown that the quantum yield of a lanthanide complex arises from a balance among the rates of several processes, e.g., ligand to $\mathrm{Ln}^{3+}$ energy transfer, multiphonon relaxation, energy back-transfer, crossover to charge-transfer states, etc. The control of these rates, as well as of other relevant physical properties, has been accomplished by a thorough selection of ligands, allowing us to develop some promising LCMDs [8,11-15], with high quantum yields at room temperature, leading to new applications $[6,7]$. We are now reporting the synthesis, spectroscopic, X-ray characterization, and photophysical investigation, as well as the molecular and electronic structure prediction with emphasis on the ligand-centered triplet energy level of the lanthanide complexes $\mathrm{Ln}(\tan )_{3}$ bipy, where $\mathrm{Ln}=\mathrm{Eu}^{3+}$ or $\mathrm{Gd}^{3+}$; $\tan =4,4,4$-trifluoro1-(1-naphthyl)-1,3-butanedionate and bipy $=2,2^{\prime}$ bipyridyl.

\section{Experimental procedure}

\subsection{Synthesis}

The starting chemicals were $\mathrm{Eu}_{2} \mathrm{O}_{3}$ 99.9\%, $\mathrm{Gd}_{2} \mathrm{O}_{3} 99.9 \%, \mathrm{La}_{2} \mathrm{O}_{3} 99.9 \%$, tan $99 \%$, and bipy 99\% all obtained from Aldrich. The above oxides have been converted into their respective chlorides through addition of $\mathrm{HCl}\left(0.7 \mathrm{~mol} \mathrm{~L}^{-1}\right)$ and successive evaporations in ethanol.

Syntheses of the $\mathrm{Eu}^{3+}$ and $\mathrm{Gd}^{3+}$ complexes were accomplished by adding a stoichiometric quantity of an ethanolic solution of the anion of $\tan (3 \mathrm{mmol})$ and an ethanolic solution of bipy $(1 \mathrm{mmol})$ dropwise to an ethanolic solution of $\mathrm{LnCl}_{3} \cdot x \mathrm{H}_{2} \mathrm{O}$. The reaction was refluxed for $12 \mathrm{~h}$ and solid compounds were obtained after solvent evaporation. $\mathrm{Eu}(\tan )_{3}$ bipy crystals suitable for $\mathrm{X}$-ray structure determination were grown from a $\mathrm{MeOH} / \mathrm{H}_{2} \mathrm{O}$ mixed solvent. The chemical analytical data of the complexes indicate the formula $\mathrm{Eu}(\tan )_{3}$ bipy (found: $\mathrm{C}, 56.16 \% ; \mathrm{H}, 3.42 \% ; \mathrm{N}$, $2.00 \%$; Calc.: C, $56.58 \%$; H, 2.92\%; N, 2.54\%).

\subsection{Spectroscopic measurements}

The UV-Vis absorption spectra were recorded with a Perkin-Elmer Lambda 6 spectrophotometer using $10^{-5} \mathrm{M}$ ethanolic solutions of the complexes. Diffuse reflectance spectra of the powder samples were recorded with a Perkin-Elmer Lambda 7 spectrophotometer equipped with an integration sphere. The IR absorption spectra were measured on a Bruker IF566 FTIR spectrophotometer using the $\mathrm{KBr}$ pellet technique.

The luminescence spectrum of the $\mathrm{Eu}^{3+}$ complex at $77 \mathrm{~K}$ was obtained under excitation at $370 \mathrm{~nm}$, by using a $150 \mathrm{~W}$ Xe lamp and a Jobin-Yvon $0.25 \mathrm{~m}$ monochromator. The luminescence was dispersed by a Jobin-Yvon double monochromator (model V-1000) and the signal was detected by a water-cooled RCA C31034-02 photomultiplier. Excitation of the $\mathrm{Gd}^{3+}$ complex was accomplished with a laser science model VSL$337 \mathrm{ND}$ laser at $330 \mathrm{~nm}$.

Excitation and luminescence spectra were also obtained by using a Spex Fluorolog DM3000F spectrofluorometer with double-grating $0.22 \mathrm{~m}$ Spex 1680 monochromators and a $450 \mathrm{~W}$ Xe lamp as the excitation source. This setup is equipped with an Oxford LF205 liquid helium flow cryostat, allowing for measurements down to $4.2 \mathrm{~K}$. The spectra were corrected for the instrumental response.

Excited state decay-time measurements were performed at 298 and $77 \mathrm{~K}$ using the third 
harmonic of an $\mathrm{Nd}-\mathrm{YAG}$ laser $(10 \mathrm{~Hz})$ as the excitation source. The emission was detected with a modified 1P28 photomultiplier tube after dispersion through a $0.25 \mathrm{~m}$ monochromator. A filter was used to cutoff any residual laser light. The signal was then analyzed on a Boxcar system (EG\&G Princeton applied research). The temporal resolution of the overall system is ca. $50 \mathrm{~ns}$.

The emission quantum yield, $q$, defined as the ratio between the number of photons emitted by the $\mathrm{Eu}^{3+}$ ion and the number of photons absorbed by the ligand, was measured according to the method described in detail elsewhere [10], which has an accuracy of $10 \%$.

The crystal structure was elucidated by X-ray diffraction analysis. The intensity data were collected on an Enraf-Nonius CAD4 diffractometer, using $\mathrm{MoK} \alpha$ radiation (graphite monochromator) in the $\varpi-2 \theta$ scan mode, at room temperature. Data were corrected for absorption using $\Psi$-scan [18] $\left(T_{\max }=0.9999, T_{\min }=0.9847\right)$. The structure was solved by SIR92 [19] and refined by SHELXL-97 [20].

\section{Theoretical procedure}

The molecular structure of $\mathrm{Eu}(\tan )_{3}$ bipy was obtained with the SMLC II (Sparkle Model for lanthanide compounds-parameterization scheme II) method [21-23] implemented within the MOPAC93 program [24]. Two starting geometries were used in the optimization procedure, namely, the experimental X-ray (structure 1) and a model structure (structure 2) constructed from a similar compound of known structure.

The absorption transitions as well as the triplet state energy levels, both ligand-centered, were calculated with the INDO/S-CIS (Intermediate neglect of differential overlap/spectroscopy parameterization-configuration interaction singly excitations) method $[25,26]$. The $\mathrm{Eu}^{3+}$ ion is replaced by a [27] $+3 e$ and a [28] $+3.5 e$ point charge. This method considers all configurations obtained by singly electron replacements (CIS) of the reference determinant within an active space. The variable point charge value is intended to investigate the imperfect shielding of the $4 \mathrm{f}$ shells from the coordinated carbonyl groups affecting the position of the $\mathrm{C}=\mathrm{O}$ centered $\pi \rightarrow \pi^{*}$ states and subsequently the triplet state energies [28].

For the $\mathrm{Eu}(\tan )_{3}$ bipy compound, an active space of 28 occupied and 16 unoccupied molecular orbitals (MOs) yielded converged results for the calculated absorption spectrum (transition energies and oscillator strengths). In order to better compare the calculated spectrum with the experimental one, a Lorentzian lineshape with a $30 \mathrm{~nm}$ bandwidth has been adjusted to the calculated results [27].

\section{Results and discussions}

It is observed that the $\mathrm{C}=\mathrm{C}$ and $\mathrm{C}=\mathrm{N}$ stretching bands shift from $1577 \mathrm{~cm}^{-1}$ and $1558 \mathrm{~cm}^{-1}$, respectively, in the free bipy ligand, to $1595 \mathrm{~cm}^{-1}$ and $1569 \mathrm{~cm}^{-1}$ in the complexes. These observations provide evidence that the metal ion is coordinated through the nitrogen atoms [29]. Another good evidence for the complexation is obtained by observations of the $\mathrm{C}=\mathrm{O}$ stretching band. It is a large band in the free tan ligand (enolic and diketone forms are possible) at $1600 \mathrm{~cm}^{-1}$ and becomes narrower in the complexes (just enolic form is expected) at $1610 \mathrm{~cm}^{-1}$.

The crystal structure of the Eu(tan) $)_{3}$ bipy complex has been elucidated by X-ray crystallography [30] (Fig. 1) and yielded the empirical formula EuC52H32O6N2F9, which is consistent with the microanalytical results. This complex crystallizes in a primitive cell with four molecules per unit cell and a monoclinic crystalline system with a symmetry spatial group $P 2_{1} / c$, which is detailed in Table 1.

The luminescence spectrum of $\operatorname{Gd}(\tan )_{3}$ bipy at $4.2 \mathrm{~K}$, presented in Fig. 2, was measured in order to determine the excited energy levels of the organic ligands that could participate in the energy transfer process to the $\mathrm{Eu}^{3+}$ in the $\mathrm{Eu}(\tan )_{3}$ bipy compound. The maximum occurs at $525 \mathrm{~nm}$ $\left(19,050 \mathrm{~cm}^{-1}\right)$ and since the correspondent $77 \mathrm{~K}$ measured decay time was $330 \mu$ s, this emission was ascribed to a triplet state. In this way, this peak is chosen as the experimental estimate of the lowest triplet energy level of the whole ligand system. 


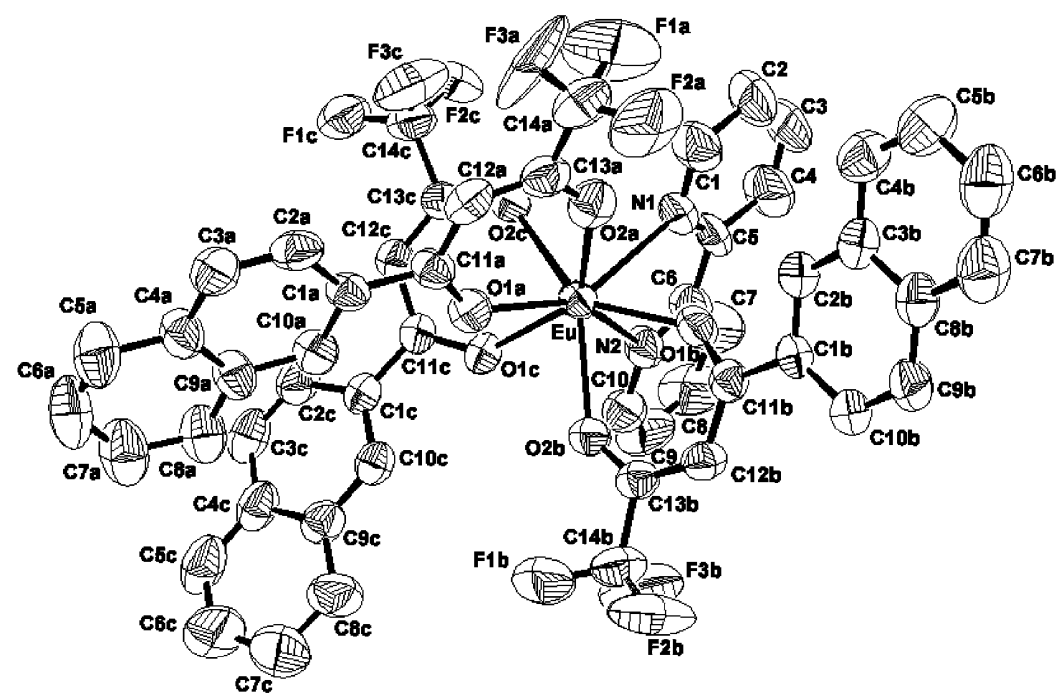

Fig. 1. ORTEP drawing of the Eu(tan) $)_{3}$ bipy complex crystallographic structure $(50.0 \%$ probability ellipsoids, except for the hydrogen atoms).

Table 1

Crystallographic data for Eu(tan) $)_{3}$ bipy

\begin{tabular}{ll}
\hline Chemical formula: & Formula weight: 1106.78 \\
$\begin{array}{l}\text { EuC }{ }_{52} \mathrm{H}_{35} \mathrm{O}_{6} \mathrm{~N}_{2} \mathrm{~F}_{9} \\
\text { crystal system: monoclinic }\end{array}$ & Space group: $P 2_{1} / c$ (No. 14) \\
$a=11.307(1) \AA$ & $T=293(2) \mathrm{K}$ \\
$b=23.497(2) \AA$ & $\lambda=0.71073 \AA$ \\
$c=17.961(2) \AA$ & $\rho_{\text {calc }}=1.553 \mathrm{~g} / \mathrm{cm}^{3}$ \\
$\beta=97.10(1)^{\circ}$ & $\mu=14.12 \mathrm{~mm}^{-1}$ \\
$V=4735.1(8) \AA^{3}$ & $R\left(F^{2}\right)=0.0445^{\mathrm{a}}$ \\
$Z=4$ & $R_{\mathrm{w}}\left(F^{2}\right)=0.0865^{\mathrm{b}}$ \\
\hline
\end{tabular}

${ }^{\mathrm{a}} R\left(F^{2}\right)=\sum\left(\left|F_{\mathrm{o}}\right|-\left|F_{\mathrm{c}}\right|\right) / \sum\left|F_{\mathrm{o}}\right|$.

${ }^{\mathrm{b}} R_{\mathrm{w}}\left(F^{2}\right)=\left[\left(\sum w\left(\left|F_{\mathrm{o}}\right|-\left|F_{\mathrm{c}}\right|\right)^{2} / \sum w\left|F_{\mathrm{o}}\right|^{2}\right)\right]^{1 / 2}$.

This state is usually considered the main channel for energy transfer to the lanthanide ${ }^{5} \mathrm{D}_{\mathrm{J}}$ states. However, in this case, the energy level of this triplet state is quite low and, thus it is not in optimal resonance conditions with the $\mathrm{Eu}^{3+}$ emitting levels $\left({ }^{5} \mathrm{D}_{\mathrm{J}}\right)$ in the energy transfer process. This statement is corroborated by the low quantum yields measured for this compound as shall be discussed below. Furthermore, the Gd(tan) $)_{3}$ bipy luminescence spectrum presents a well resolved vibrational progression, where the shortest wave-

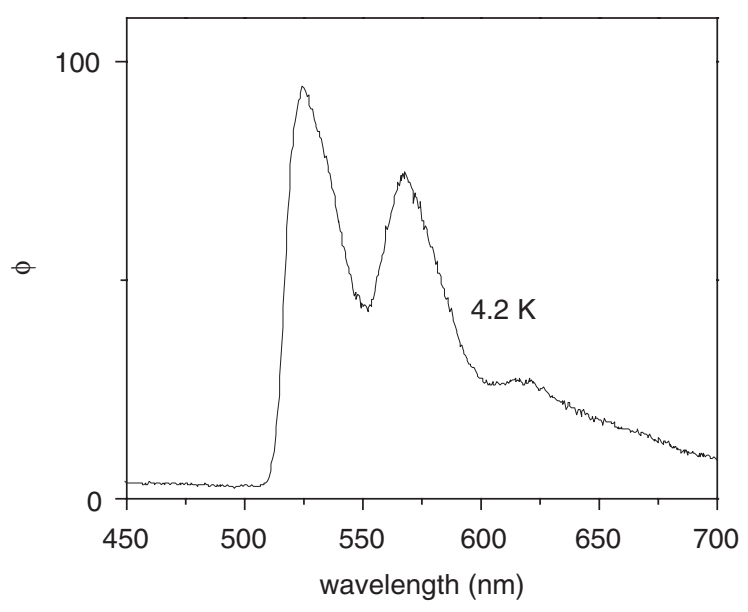

Fig. 2. Luminescence spectrum of $\mathrm{Gd}(\tan )_{3}$ bipy at $4.2 \mathrm{~K}$, upon ligand excitation $(330 \mathrm{~nm})$. $\phi$ gives the radiant power per constant wavelength interval in arbitrary units.

length band, the band maximum at $525 \mathrm{~nm}$, is assigned to the $0-0$ phonon line, whereas the two following bands with decreasing intensities, at 565 and $625 \mathrm{~nm}$, are assigned to the $0-1$ and $0-2$ phonon lines, respectively. This spectrum is characteristic of an emitting excited state with a energy potential curve that has little displacement of its minimum in comparison to the ground state 


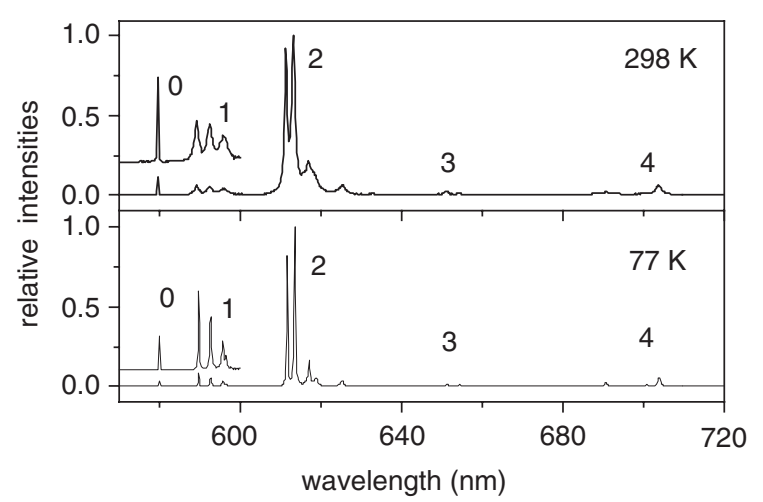

Fig. 3. Luminescence spectra of the powdered Eu(tan) $)_{3}$ bipy complex at 298 and $77 \mathrm{~K}$ excited at $370 \mathrm{~nm}$. The labels refer to the $J$ values of the final level of the emission transition ${ }^{5} \mathrm{D}_{0} \rightarrow{ }^{7} \mathrm{~F}_{\mathrm{J}}$. The insets shows the ${ }^{5} \mathrm{D}_{0} \rightarrow{ }^{7} \mathrm{~F}_{0,1}$ region magnified.

potential curve minimum, which would correspond to a small Huang-Rhys coupling constant, $S$ [31], commonly used in the solid state literature, $S \sim 1$ (weak-to-intermediate coupling case). This behavior will be, as seeing below, important in the nonradiative deactivation of the $\mathrm{Eu}(\tan )_{3}$ bipy compound luminescence at room temperature.

The luminescence spectra at 298 and $77 \mathrm{~K}$ of the powdered Eu(tan) $)_{3}$ bipy complex are presented in Fig. 3. The emission lines of $\mathrm{Eu}^{3+}$ complex were attributed to ${ }^{5} \mathrm{D}_{0} \rightarrow{ }^{7} \mathrm{~F}_{\mathrm{j}}$ transitions. The ${ }^{5} \mathrm{D}_{0} \rightarrow{ }^{7} \mathrm{~F}_{1}$ transition presents three large bands where one of them is split, possibly due to a vibronic effect. The hypersensitive transition ${ }^{5} \mathrm{D}_{0} \rightarrow{ }^{7} \mathrm{~F}_{2}$ shows best resolution at $77 \mathrm{~K}$ as is shown in Fig. 3.

The luminescence spectrum at $298 \mathrm{~K}$ of the $\mathrm{Eu}(\tan )_{3}$ bipy in the single-crystalline material is similar to that of the powdered. The spectrum of the crystal was also measured at $77 \mathrm{~K}$ (Fig. 3), and indicates the existence of a low symmetry but a single site for the $\mathrm{Eu}^{3+}$ ion, which was previously observed by X-ray diffraction analysis.

As mentioned above, at temperatures lower than $120 \mathrm{~K}$ the $\mathrm{Gd}^{3+}$ complex shows a broadband green luminescence upon UV excitation (Fig. 2), which is ascribed to the triplet ligand states. This emission is completely absent in the $\mathrm{Eu}^{3+}$ complex, even at $4.2 \mathrm{~K}$, indicating the occurrence of ligand to $\mathrm{Eu}^{3+}$ energy transfer. Nevertheless, the quantum yield of the $\mathrm{Eu}^{3+}$ emission in the

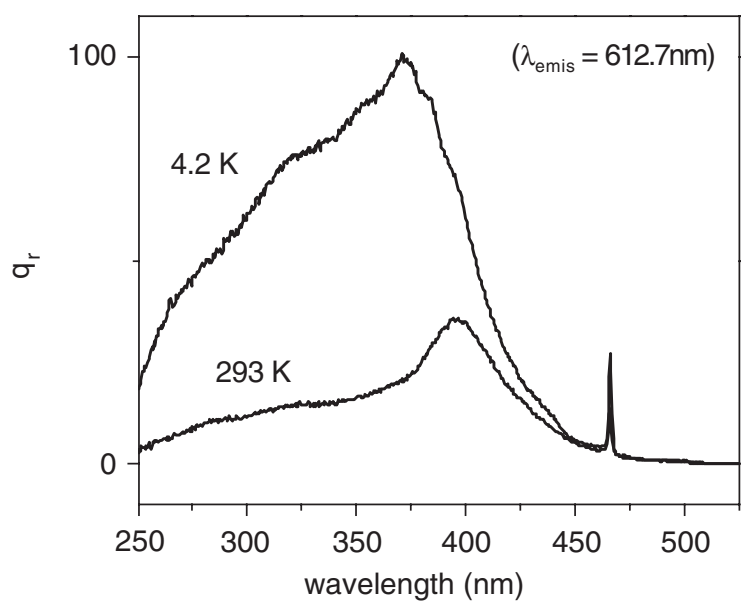

Fig. 4. Excitation spectra of the $\mathrm{Eu}^{3+}$ luminescence (emission wavelength at $612.7 \mathrm{~nm}$ ) in Eu(tan) $)_{3}$ bipy complex at 293 and $4.2 \mathrm{~K} . q_{\mathrm{r}}$ gives the relative external quantum yield.

$\mathrm{Eu}(\tan )_{3}$ bipy complex is rather low at $300 \mathrm{~K}$ (viz. $7 \%$ ). It is probably due to the too low energy of the triplet ligand state, namely $19,050 \mathrm{~cm}^{-1}$, poorly resonant with the ${ }^{5} \mathrm{D}_{2}$ state $\left(21,000 \mathrm{~cm}^{-1}\right)$ of the $\mathrm{Eu}^{3+}$ ion, which is believed, as it was recently proposed [32], to be the most important channel for an efficient luminescence via the exchange mechanism. Another interesting aspect is that the quantum yield of the $\mathrm{Eu}^{3+}$ emission increases by a factor of three $(7-21 \%)$ when the temperature is lowered to $4.2 \mathrm{~K}$ (Fig. 4). This observation implies the existence of a quenching state whose population is strongly temperature dependent. Usually, the crossover from the ${ }^{5} \mathrm{D}_{0}$ emitting state (or from its feeding levels) to a charge transfer (CT) state involves an energy barrier and it is therefore strongly dependent on the temperature [9]. The charge transfer state will then be depopulated via nonradiative decay to the ground state, therefore, resulting in quenching of the $\mathrm{Eu}^{3+}$ luminescence $[9,31,33]$. Since the available thermal energy at $4.2 \mathrm{~K}$ is small, it seems likely that the crossover rate to the CT state would be very slow at this temperature, thus this quenching channel would not be significant. However, at higher temperatures the thermally activated crossover to the CT state becomes faster, therefore, leading to a larger degree of quenching and a lower emission 
quantum yield. Other important nonradiative losses of the system are through ion states $(4 \mathrm{f}-4 \mathrm{f}$ transition) or via the lowest ligand triplet level after an energy back-transfer $\mathrm{Eu}^{3+}$-to-ligand process. Among these processes, the last one involves an energy barrier, as in the CT case, and is exponentially dependent upon temperature. Based on these statements, we suggest that the reasons for this large decrease of the quantum yield through lowering the temperature are twofold: (i) a significant energy back-transfer from the $\mathrm{Eu}^{3+}$ states to the ligand states, which being ligand-centered decay nonradiatively and; (ii) energy transfer from either ligand or $\mathrm{Eu}^{3+}$ states to the LMCT states that acts as quencher states due to nonradiative decay.

Fig. 4 shows that the dependence of the $\mathrm{Eu}^{3+}$ luminescence quenching with the temperature is not the same for all the excitation wavelengths, being more pronounced for wavelengths shorter than ca. $400 \mathrm{~nm}$. We can assume that the energy back-transfer from the $\mathrm{Eu}^{3+}$ to the ligand states mechanism is weakly dependent upon the excitation wavelength, whereas the opposite behavior is expected for the energy transfer from the ligand to the LMCT states, since LMCT states with higher energies would become viable. Thus, for excitation wavelengths shorter than $400 \mathrm{~nm}$ it is expected that the quenching through LMCT states dominate. Whereas, for excitation wavelengths longer than $400 \mathrm{~nm}$ it is expected a competition between these two mechanisms. Also, the ${ }^{5} \mathrm{D}_{0}$ lifetime is not strongly temperature dependent, changing from $447 \mu \mathrm{s}$ at $300 \mathrm{~K}$ to $432 \mu \mathrm{s}$ at $77 \mathrm{~K}$. This suggests that there should not be any LMCT states with energies near the ${ }^{5} \mathrm{D}_{0}$ one and that the nonradiative depopulation of the ${ }^{5} \mathrm{D}_{0}$ state via back-energy transfer to the ligand triplet states should be negligible. As a result, we can infer that the LMCT states have energies larger than $25,000 \mathrm{~cm}^{-1}$, that is $\lambda>400 \mathrm{~nm}$, and they are the dominating states for luminescence quenching in the $\mathrm{Eu}(\tan )_{3}$ bipy complex at any temperature and excitation wavelength.

The absorption spectrum of the Eu(tan) $)_{3}$ bipy complex in ethanolic solution is presented in Fig. 5 together with the theoretical predictions. It can be seen three broad bands with maxima at 257, 289 and $334 \mathrm{~nm}$, the second one being the least intense. These bands have been assigned to $\pi \rightarrow \pi^{*}$ like ligand-centered transitions.

The ligand-centered absorption spectra of the $\mathrm{Eu}(\tan )_{3}$ bipy complex has been calculated with the INDO/S-CIS method using both a +3.0 and +3.5 point charge representing the lanthanide ion [28]. The reasoning for using a larger than +3.0 point charge has been discussed elsewhere [28], and as it can be seen from Fig. 5, the spectrum calculated with the +3.5 point charge is in better agreement with the experimental one than that using a +3.0 point charge. It should also be noted that there are no significant differences between the calculated spectra of the structures 1 (X-ray) and 2 (model), except near $240 \mathrm{~nm}$, where structure 2 yields a small shoulder, which is absent in the spectrum of structure 1. These results show that despite the differences in the starting structures, the SMLC II method is quite robust and yields optimized structures that have almost identical absorption spectra. In Table 2 the comparison between the calculated and experimental data regarding the energy levels of the $\mathrm{Eu}(\tan )_{3}$ bipy complex is presented and it can be observed a very good agreement between the experimental and theoretical energy levels. The experimental absorption

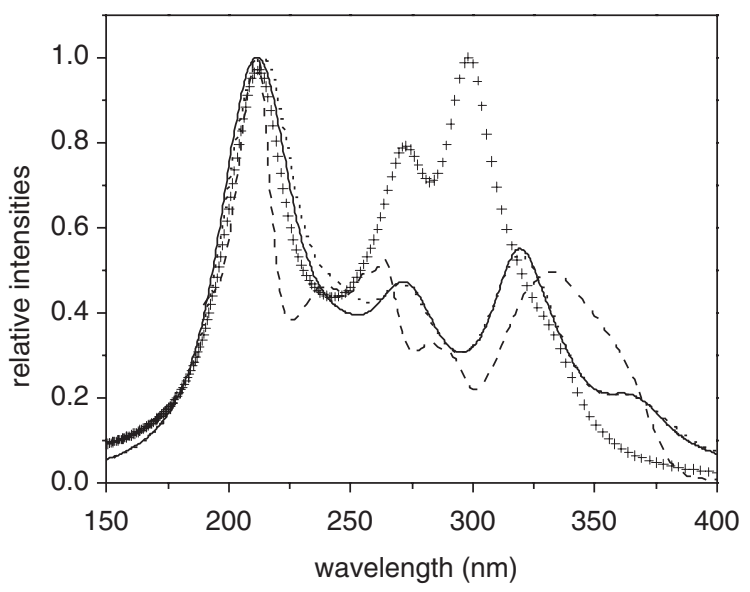

Fig. 5. Experimental ethanolic solution (dashed line) and theoretical absorption spectra of the Eu(tan) $)_{3}$ bipy complex obtained with a +3.0 point charge with structure $1(+++)$, a +3.5 point charge with structure 1 (solid line) and a +3.5 point charge with structure 2 (dotted line). 
Table 2

Theoretical $(+3.5 e$ point charge) and experimental ligand-centered energy levels

\begin{tabular}{|c|c|c|c|c|c|}
\hline \multirow[t]{3}{*}{ Structure } & \multicolumn{3}{|l|}{ Singlet } & \multirow{2}{*}{\multicolumn{2}{|c|}{ Triplet energy $\left(\mathrm{cm}^{-1}\right)$}} \\
\hline & \multirow{2}{*}{$\frac{\text { Experimental }}{\text { Energy }\left(\mathrm{cm}^{-1}\right)}$} & \multicolumn{2}{|l|}{ Theoretical } & & \\
\hline & & Energy $\left(\mathrm{cm}^{-1}\right)$ & Oscillator strengths & Experimental & Theoretical \\
\hline & 30,303 & 31,553 & 1.92 & 19,050 & \\
\hline \multirow{4}{*}{ (X-ray) } & & 29,953 & 0.32 & & 18964 \\
\hline & 27,397 & 27,796 & 0.2 & & 18746 \\
\hline & & 27,123 & 0.25 & & 18297 \\
\hline & 30,303 & 30,459 & 0.33 & & \\
\hline 2 & & 29,977 & 0.19 & 19,050 & 19016 \\
\hline \multirow[t]{3}{*}{ (model) } & & 27,914 & 0.25 & & 18797 \\
\hline & 27,397 & 27,471 & 0.12 & & 18723 \\
\hline & & 26,447 & 0.2 & & \\
\hline
\end{tabular}

spectrum presents only a maximum at $30,303 \mathrm{~cm}^{-1}$ and a large shoulder at longer wavelength $27,397 \mathrm{~cm}^{-1}$. From Table 2 it can be observed that the largest theoretical oscillator strengths are found at the same region. Also in Table 2, a good agreement can be observed between the experimental and the theoretical triplet energy levels, which is slightly red shifted.

\section{Conclusions}

Insights into the electronic structure of the $\mathrm{Eu}(\tan )_{3}$ bipy complex, focusing the role of the ligand triplet state in the energy transfer process, as well as the temperature dependence of its luminescence quantum yield based on the presence of a LMCT state have been provided. The experimental and theoretical calculations are consistent and could help to improve the design of new luminescent materials and to understand the ligand-lanthanide energy transfer process at the electronic level.

\section{Acknowledgements}

The authors acknowledge to the CNPq, PADCT, CAPES, FACEPE and FINEP (Brazilian agencies) and ACS-PRF for financial support.
We acknowledge Dra. Teresa Maria do Prado Gambardella for X-ray analysis at USP-SP, and Dr. Jorge Menezes for microanalysis. We are indebted to Prof. A. Meijerink (Universiteit Utrecht, The Netherlands) for kindly allowing the use of his laboratory facilities.

\section{References}

[1] G.R. Choppin, J.-C.G. Bunzli (Eds.), Lanthanides Probes in Life Chemical and Earth Sciences, Elsevier, Amsterdam, 1989.

[2] L.A. Hemmilä, Applications of fluorescence in immunoassays, Willey, New York, 1989.

[3] G. Mathis, Clin. Chem. 41 (1995) 1391.

[4] C.R. Ronda, J. Alloys Comp. 225 (1995) 534.

[5] N. Sabbatini, M. Guardigli, J.-M. Lehn, Coord. Chem. Rev. 123 (1993) 201.

[6] C.G. Gameiro, E.F. da Silva Jr., S. Alves Jr., G.F. de Sá, P.A. Santa-Cruz, Mat. Forum 315 (1999) 249.

[7] G.F. de Sá, S. Alves Jr., B.J.P. da Silva, E.F. da Silva Jr., Opt. Mater. 11 (1998) 23.

[8] C. de Mello Donegá, S. Alves Jr., G.F. de Sá, Chem. Commun. (1996) 1199.

[9] C. de Mello Donegá, S.J.L. Ribeiro, R.R. Gonçalves, G. Blasse, J. Phys. Chem. Solids 57 (1996) 1727.

[10] C. de Mello Donegá, S. Alves Jr., G.F. de Sá, J. Alloys Comp. 250 (1997) 422.

[11] S. Alves Jr., F.V. Almeida, G.F. de Sá, C. de Mello Donegá, J. Lumin. 478 (1997) 72.

[12] M.E. Mesquita, G.F. de Sá, O.L. Malta, J. Alloys Comp. 250 (1997) 417. 
[13] O.L. Malta, H.F. Brito, J.F.S. Menezes, F.R.G. e Silva, S. Alves Jr., F.S. Farias Jr., A.V.M. de Andrade, J. Lumin. 75 (1997) 255.

[14] O.L. Malta, H.F. Brito, J.F.S. Menezes, F.R.G. e Silva, C. de Mello Donegá, S. Alves Jr., Chem. Phys. Lett. 282 (1998) 233.

[15] H.J. Batista, A.V.M. de Andrade, R.L. Longo, A.M. Simas, G.F. de Sá, N.K. Ito, L.C. Thompson, Inorg. Chem. 37 (1998) 3542.

[16] B.S. Santos, C. de Mello Donegá, G.F. de Sá, L.F.C. de Oliveira, P.S. Santos, Spectrochim. Acta A 54 (1998) 2237.

[17] G.F. de Sá, O.L. Malta, C. de Mello Donegá, A.M. Simas, R.L. Longo, P.A. Santa-Cruz, E.F. da Silva Jr., Coord. Chem. Rev. 196 (2000) 165.

[18] A.C. North, D.C. Phillips, F.S. Mathews, Acta Crystallogr. A 24 (1968) 351.

[19] A. Altomare, G. Cascarano, G. Giacovazzo, A. Guagliardi, M.C. Burla, G. Polidori, M. Camalli, J. Appl. Crystallogr. 27 (1994) 1045.

[20] G.M. Sheldrick, SHELXL97: Program for the Refinement of Crystal Structures, University of Göttingen, Germany, 1997.

[21] A.V.M. de Andrade, N.B. da Costa Jr., A.M. Simas, G.F. de Sá, Chem. Phys. Lett. 227 (1994) 349.
[22] A.V.M. de Andrade, N.B. da Costa Jr., A.M. Simas, G.F. de Sá, J. Alloys Comp. 225 (1995) 55.

[23] A.V.M. de Andrade, N.B. da Costa Jr., R.L. Longo, O.L. Malta, A.M. Simas, G.F. de Sá, Mol. Eng. 7 (1997) 293.

[24] M.B. Coolidge, J.J.P. Stewart, MOPAC Manual, Franck J. Seiler Research Laboratory, US Air Force Academy, CO, 1990.

[25] J. Ridley, M.C. Zerner, Theoret. Chim. Acta 32 (1973) 111.

[26] J. Ridley, M.C. Zerner, Theor. Chim. Acta 42 (1976) 223.

[27] A.V.M. de Andrade, R.L. Longo, A.M. Simas, G.F. de Sá, J. Chem. Soc. Faraday Trans. 92 (1996) 1835.

[28] H.J. Batista, R.L. Longo, Int. J. Quantum Chem. 90 (2002) 924.

[29] R.L. Shriner, The Systematic Identification of Organic Compounds, Wiley, New York, 1980.

[30] M.N. Brunett, C.K. Johnson, ORTEPIII. Report ORNL6895, OAK Ridge National Laboratoty, Tennessee, USA, 1996.

[31] G. Blasse, B.C. Grabmaier, Luminescent Materials, Springer, Berlim, 1994.

[32] F.R.G. e Silva, O.L. Malta, J. Alloys Comp. 250 (1997) 427.

[33] L. van Pieterson, Charge Transfer and $4 \mathrm{f}^{n} \rightarrow 4 \mathrm{f}^{n-1} 5 \mathrm{~d}$ Luminescence of Lanthanide Ions, Ph.D. Thesis, Utrecht, Netherlands, 2001. 